\title{
HOSPITAL MALNUTRITION AND INFLAMMATORY RESPONSE IN CRITICALLY ILL CHILDREN AND ADOLESCENTS ADMITTED TO A TERTIARY INTENSIVE CARE UNIT
}

\author{
Artur F. Delgado, Thelma S. Okay, Claudio Leone, Buford Nichols, Gilda \\ Maria Del Negro, Flávio Adolfo Costa Vaz
}

doi: $10.1590 / \mathbf{S 1 8 0 7 - 5 9 3 2 2 0 0 8 0 0 0 3 0 0 0 1 2}$

\begin{abstract}
Delgado AF, Okay TS, Leone C, Nichols B, Del-Negro GM, Costa-Vaz FA. Hospital malnutrition and inflammatory response in critically ill children and adolescents admitted to a tertiary intensive care unit. Clinics. 2008;63:357-62.
\end{abstract}

Critical illness has a major impact on the nutritional status of both children and adults. A retrospective study was conducted to evaluate the incidence of hospital malnutrition at a pediatric tertiary intensive care unit (PICU). Serum concentrations of IL-6 in subgroups of well-nourished and malnourished patients were also evaluated in an attempt to identify those with a potential nutritional risk.

METHODS: A total of 1077 patients were enrolled. Nutritional status was evaluated by Z-score (weight for age). We compared mortality, sepsis incidence, and length of hospital stay for nourished and malnourished patients. We had a subgroup of 15 patients with severe malnutrition $(\mathrm{MN})$ and another with 14 well-nourished patients (WN). Cytokine IL-6 determinations were performed by enzyme-linked immunosorbent assay.

RESULTS: $53 \%$ of patients were classified with moderate or severe malnutrition. Similar amounts of C- reactive protein (CRP) were observed in $\mathrm{WN}$ and $\mathrm{MN}$ patients. Both groups were able to increase IL-6 concentrations in response to inflammatory systemic response and the levels followed a similar evolution during the study. However, the mean values of serum IL-6 were significantly different between WN and MN patients across time, throughout the study $(\mathrm{p}=0.043)$.

DISCUSSION: a considerable proportion of malnourished patients need specialized nutritional therapy during an intensive care unit (ICU) stay. Malnutrition in children remains largely unrecognized by healthcare workers on admission.

CONCLUSIONS: The incidence of malnutrition was very high. Malnourished patients maintain the capacity to release inflammatory markers such as CRP and IL-6, which can be considered favorable for combating infections On the other hand, this capacity might also have a significant impact on nutritional status during hospitalization.

KEYWORDS: Nutritional status. Critical care. Hospitalization. Interleukins. Sepsis.

\section{INTRODUCTION}

Systemic inflammatory response causes metabolic deregulation leading to muscle proteolysis (hypercatabolism) ${ }^{1}$ and the release of cytokines and chemokines in critically ill patients. The resulting negative nitrogen balance is usually proportional to the intensity of the injury ${ }^{2}$. Interleukin 6

Unidade de Terapia Intensiva do Instituto da Criança "Prof Pedro de Alcantara" do Hospital das Clínicas da Faculdade de Medicina da Universidade de São Paulo - São Paulo/SP, Brazil. arturdf@terra.com.br

Received for publication on December 29, 2007

Accepted for publication on March 24, 2008
(IL-6), a proinflammatory cytokine recognized as an early marker of the Systemic Inflammatory Response Syndrome (SIRS) in several disease models, might be used to determine whether the inflammatory response is intact. ${ }^{3,4}$ More recently, serum concentrations of IL- 6 have been associated with the capacity to identify patients with a potential nutritional risk. ${ }^{1,3,4}$

Although hospital malnutrition constitutes an important risk factor for increases in morbidity, lethality, length of hospital stay, and medical costs, it is troublesome to assess the impact of acute hospitalization on the nutritional status of critically ill children. ${ }^{5,6}$ Associations have been reported between poor nutritional status, decreased respiratory 
function, impaired wound healing, and immune and gastrointestinal dysfunctions. ${ }^{4,7,8}$

The diagnosis of malnutrition is generally based on objective measurements of nutritional status, including assessments of oral intake, weight loss, anthropometric data, determination of cell-mediated immunity, biochemical parameters, and body composition analysis. ${ }^{6.9}$ Despite its high prevalence, malnutrition is seldom recognized by pediatricians in hospitalized patients. As a consequence, nutritional therapy is underprescribed, thus compounding the problem. Therefore, assessment of the nutritional status of patients is important as a guide to early nutritional intervention. ${ }^{10-12}$

Malnutrition is common at hospital admission and tends to worsen during hospitalization. In Europe and North America, $40-50 \%$ of hospitalized patients are at risk of malnutrition. Several studies performed in Brazil and in other countries demonstrated that malnutrition can affect $50 \%$ of children and adolescents during hospitalization, although the classical kwashiorkor presentation is rare in critically ill infants, children, and adolescents with chronic diseases such as those in our ICU. In general, little is known about the nutritional status of critically ill children during hospitalization in, and after discharge from, ICUs. Critical illness has a major impact on the nutritional status of both children and adults. Studies conducted more than 20 years ago had already demonstrated that $15-20 \%$ of children admitted to pediatric intensive care units were acutely or chronically malnourished. ${ }^{10-14}$

We conducted a retrospective study to evaluate the incidence of hospital malnutrition in children and adolescents during the first 72 hours after admission in our tertiary intensive care unit. We also evaluated serum concentrations of IL-6 and C- reactive protein (CRP) in groups of wellnourished and malnourished patients, in an attempt to determine those with a potential nutritional risk.

\section{PATIENTS AND METHODS}

The study was approved by the Institutional Research Ethics Committee. A total of 1077 children and adolescents admitted from March, 2002 to February, 2005 to our level III pediatric ICU were enrolled. We classified the nutritional status by Z-score weight for age in all patients admitted during this period. We considered a Z score of (-2) or lower as moderate or severe malnutrition. We compared mortality, sepsis incidence, and length of hospital stay for nourished and malnourished patients. The patient data were recorded, and $\mathrm{Z}$ scores were calculated for body weight/age using the EPI 2000 program from the Centers for Disease Control and Prevention (Atlanta, GA., USA). This software uses the National Center for Health Statistics 2000 (NCHS) reference values. We used a nonparametric statistic analysis (KruskalWallis test) to test the data.

Twenty-nine critically ill children and adolescents aged between two months and 16 years were included in two groups selected from the total population of 1077 children. We had a group of 15 patients with severe malnutrition (MN) and another with 14 well-nourished patients (WN), all of 29 presenting with SIRS according to a consensus conference on pediatric sepsis ${ }^{15}$. The two subgroups were, for convenience, recruited by sequential sampling according to the order of hospitalization during the period of study. Severity of illness was measured at admission by the Pediatric Risk of Mortality score $^{16}$ (PRISM) and the Therapeutic Intervention Scoring System $^{17}$ (TISS, repeated on the fifth and tenth days). The nutritional evaluation was comprised of: $\mathrm{Z}$ scores calculated for body weight/age and weight/length, upper arm muscle circumference, serum C-reactive protein (CRP) and albumin. Interleukin 6 serum levels, representing the magnitude of inflammatory response, were compared between $\mathrm{MN}$ and $\mathrm{WN}$ on the first, fifth, and tenth days. All patients received early parenteral and/or enteral nutrition with standardized calorie and protein levels. Newborn babies, patients with leucopenia (total leucocyte count $<1000 \mathrm{~mm}^{3}$ ), severe liver dysfunction or who received corticosteroids for more than 72 hours were excluded.

Serum cytokine IL- 6 determinations were performed by means of an enzyme-linked immunosorbent assay, according to the manufacturer instructions (R\&D Systems, Abington, UK). Each sample was tested in triplicate, and the mean value was obtained. The IL- 6 detection limit was $0.7 \mathrm{pg} / \mathrm{mL}$. Cytokine concentrations in malnourished and well-nourished patients were compared using two-way ANOVA for repeated measures.

\section{RESULTS}

Of the total population (1077 patients), 53\% were classified with moderate or severe malnutrition. When only infants were analyzed, the incidence of moderate and severe malnutrition was even higher (58\%). The general mortality rate was $18.5 \%$. Table 1 shows the mortality rate, sepsis incidence, and period of hospitalization in the ICU in wellnourished, moderately malnourished $[\mathrm{Z}$ score between $(-1)$ and (-2)], and severely malnourished patients.

When we analyzed the two groups (MN and WN), containing 29 patients, there were no significant gender differences. Table 2 summarizes the subgroup characteristics. PRISM and TISS clinical scores indicated similar severity of illness in both groups throughout the study (Figure 1). The median ages of malnourished and well-nourished patients were 25.6 months and 10.7 months, respectively. One well- 
Table 1 - Mortality rate, sepsis incidence and the period of hospitalization at the ICU in well-nourished, moderate malnourished and severe malnourished patients

\begin{tabular}{lccc}
\hline & Well-nourished & Moderate malnourished & Severe malnourished \\
\hline Mortality rate & $18.5 \%$ & $19.5 \%$ & $17.9 \%$ \\
Sepsis incidence & $34 \%$ & $39 \%$ & $36 \%$ \\
Period of hospitalization at the ICU & 5 days & 5 days & 8 days \\
\hline
\end{tabular}

$\mathrm{n}=1077$ patients; $*$ There was not significant difference when the groups were compared.

nourished and four malnourished patients died during the evaluation.

Malnourished patients had lower mean $( \pm \mathrm{SD}) \mathrm{Z}$ scores for weight/age $(-3.1 \pm 2.0)$ and for weight/length $(-1.4 \pm$ $2.3)$ on the first day, as compared to the mean $\mathrm{Z}$ scores for weight/age $(0.2 \pm 0.9)$ and weight/length $(1.1 \pm 1.5)$ in wellnourished children and adolescents. Z scores of weight/age worsened $(\mathrm{p}<0.05)$ only in well-nourished patients during the period of the study (Table 3 ). Table 4 shows the evolution

Table 2 - Description of the diagnosis of the 29 selected patients according to age

\begin{tabular}{ll}
\hline Malnourished (Mn) & Well-nourished (Wn) \\
\hline Median of age months = 25.6 & Median of age in months = 10.7 \\
NCS tumor (pneumonia and sepsis) & Seizures (ARDS and sepsis) \\
Cardiac malformation (sepsis) & Bilateral pneumonia (sepsis) \\
Pneumonia (sepsis) & Atopic Eczema (sepsis) \\
Myocarditis (pneumonia and sepsis) & Seizures (peumonia and sepsis) \\
Leukemia (sepsis) & Pleural empyema (sepsis) \\
Cutaneous Leishmaniosis (sepsis) & Mandibular abscess (sepsis) \\
Short Bowel Syndrome (sepsis) & Pleural empyema (sepsis) \\
Pulmonary hypertension (pneumonia & Pneumonia (sepsis) \\
and sepsis) & \\
Peritonitis (sepsis) & Pneumonia (sepsis) \\
Megacolon (sepsis) & Renal malformation (sepsis) \\
Encephalopathy (gastroenteritis and & Bronchopleural fístula (sepsis) \\
sepsis) & \\
Meningitis (sepsis) & Cardiac dysfunction (pneumonia \\
$\begin{array}{l}\text { Neonatal asphyxia (pneumonia and } \\
\text { sepsis) }\end{array}$ & Pneumonia (sepsis) \\
Pneumonia and sepsis & Pleural empyema (sepsis) \\
Renal infection (sepsis) &
\end{tabular}

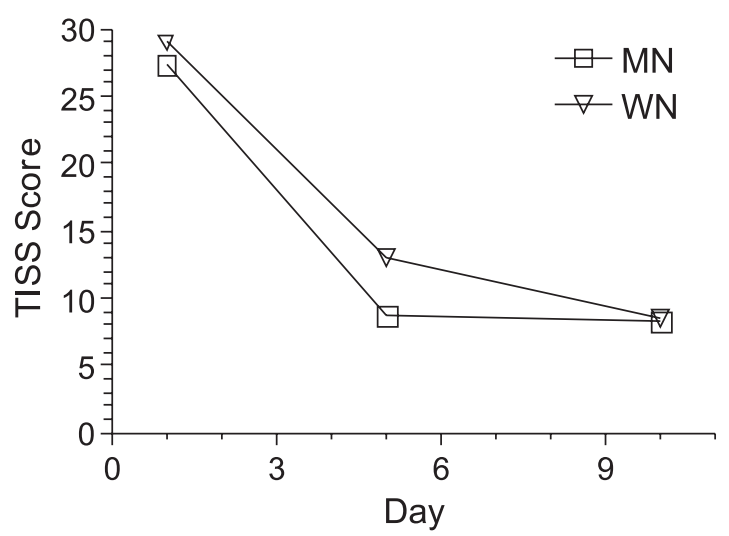

$\mathrm{n}=29$ patients

Figure 1 - Therapeutic Intervention Scoring System (TISS) evolution in Mn and $\mathrm{Wn}$ patients during the period of study

of results for upper arm muscle circumference, CRP, and albumin. Similar amounts of CRP were observed in WN and $\mathrm{MN}$ patients. There were no albumin concentration differences during the study in either group. There were no significant differences between the groups with respect to the upper arm muscle circumference. However, there were significant decrements in other well-nourished group parameters during the study period.

Age had no influence on IL-6 levels. Both groups were able to increase IL- 6 concentrations and levels underwent a similar evolution during the study. However, the mean values of serum IL-6 were significantly different between Wn and Mn patients across time $(\mathrm{p}=0.043)$. Tables 5 and 6 and Figure 2 show the results with repeated mean measures.

Table 3 - Z score for weight/age and weight/length in malnourished and well-nourished patients on the first, fifth and tenth days

\begin{tabular}{|c|c|c|c|c|c|}
\hline \multirow{2}{*}{\multicolumn{2}{|c|}{ Day }} & \multicolumn{2}{|c|}{ Weight/ age } & \multicolumn{2}{|c|}{ Weight/ length } \\
\hline & & Well-nourished & Malnourished & Well-nourished & Malnourished \\
\hline 1th & Mean \pm SD & $0.2 \pm 0.9$ & $-3.1 \pm 2.0$ & $1.1 \pm 1.5$ & $-1.4 \pm 2.3$ \\
\hline 5 th & Mean \pm SD & $-0.3 \pm 1.1$ & $-3.1 \pm 2.0$ & $0.1 \pm 2.0$ & $-1.8 \pm 2.4$ \\
\hline 10th & Mean \pm SD & $-0.5 \pm 1.1$ & $-2.5 \pm 1.7$ & $0.3 \pm 2.0$ & $-1.6 \pm 3.3$ \\
\hline
\end{tabular}

$\mathrm{n}=29$ patients 
Table 4 - Means values of upper arm muscle circumference, concentrations of albumin and C-reactive protein in malnourished and well-nourished patients during the study

\begin{tabular}{|c|c|c|c|c|c|c|c|}
\hline & \multirow[b]{2}{*}{ Day } & \multicolumn{3}{|c|}{ Malnourished } & \multicolumn{3}{|c|}{ Well-nourished } \\
\hline & & $\begin{array}{l}\text { Upper arm muscle } \\
\text { circumference }(\mathrm{cm})\end{array}$ & Albumin (g/dL) & $\begin{array}{c}\text { C-Reactive protein } \\
(\mathrm{mg} / \mathrm{L})\end{array}$ & $\begin{array}{l}\text { Mid upper arm cir- } \\
\text { cumference }(\mathrm{cm})\end{array}$ & Albumin (g/dL) & $\begin{array}{c}\text { C-Reactive protein } \\
(\mathrm{mg} / \mathrm{L})\end{array}$ \\
\hline 1 th & Mean \pm SD & $10.6 \pm 2.8$ & $3.1 \pm 0.8$ & $129.9 \pm 124.6^{*}$ & $10.7 \pm 1.1 * *$ & $2.8 \pm 0.7$ & $110.5 \pm 115.6^{* * * *}$ \\
\hline 5 th & Mean \pm SD & $9.9 \pm 3.4$ & $3.4 \pm 0.9$ & $54.4 \pm 99.2$ & $9.7 \pm 1.8$ & $3.3 \pm 0.7$ & $45.5 \pm 45.2$ \\
\hline 10th & Mean \pm SD & $10.4 \pm 3.7$ & $3.3 \pm 0.9$ & $54.9 \pm 79.6^{*}$ & $9.1 \pm 1.6^{* *}$ & $3.3 \pm 0.7$ & $25.8 \pm 30.0 * * *$ \\
\hline
\end{tabular}

$\mathrm{n}=29$ patients; $* \mathrm{p}<0.05 ; * * \mathrm{p}<0.05 ; * * * \mathrm{p}<0.05$ during the period of the study in each group - Fisher test; Albumin reference data: 0 until 1 year: $2,9-5,5 \mathrm{~g} / \mathrm{dL} ; 1$ until 31 years: 3,5 until $5,0 \mathrm{~g} / \mathrm{dL}$

Table 5 - Descriptive statistics with estimated marginal means of IL-6

\begin{tabular}{lccccccc}
\hline \multirow{2}{*}{ Day } & \multicolumn{3}{c}{ Malnourished } & & \multicolumn{3}{c}{ Well-nourished } \\
\cline { 2 - 4 } & 1 th & 5 th & 10 th & & 1 th & 5th & 10 th \\
\hline Mean \pm SD & $53.73 \pm 63.5$ & $39.32 \pm 50.9$ & $67.38 \pm 141.0$ & & $127.21 \pm 181.3$ & $52.60 \pm 43.3$ & $18.81 \pm 22.6$ \\
\hline
\end{tabular}

$\mathrm{n}=29$ patients; $* \mathrm{SD}=$ standard deviation; Considered normal serum levels $=3.5 \mathrm{pg} / \mathrm{mL} ; \mathrm{R} \& D$ systems, $\mathrm{UK}$

Table 6 - Repeated measures ANOVA for IL-6, adjusted for age and with log transformation

\begin{tabular}{lll}
\hline Effect & Descriptive level $(\mathrm{p})$ & Conclusion \\
\hline Day* Group & $\mathrm{p}=0.26$ & $\begin{array}{l}\text { There was no difference, only } \\
\text { with time }\end{array}$ \\
Group & $\mathrm{p}=0.043$ & $\begin{array}{l}\text { Mean values had significant } \\
\text { difference between Wn and } \\
\text { Mn across time }\end{array}$ \\
\hline
\end{tabular}

$\mathrm{n}=29$ patients

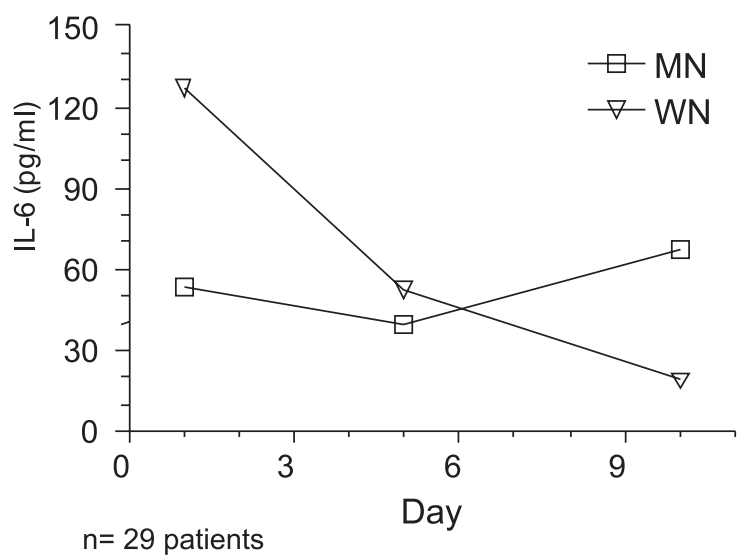

Figure 2 - IL-6 serum concentrations in malnourished and well-nourished patients during the period of the study

\section{DISCUSSION}

In a study following pediatric critical care children, Hulst et al. described in 2004 that these patients had a poor nutritional status very frequently compared to that of the general population. In their study, $24 \%$ of children were acutely and/or chronically undernourished. The period of illness prior to admission and/or the high prevalence of underlying disease in these children (84\%) could explain this high proportion. They concluded that a considerable proportion of malnourished patients need specialized nutritional therapy during ICU stays ${ }^{9}$. These characteristics were very similar to those found in the present study, with a high prevalence of malnutrition in children and adolescents admitted to our tertiary ICU. Öztürk et al. reported that, in well-nourished children, there was no deterioration of their anthropometric values during hospitalization. However, there was also no improvement in anthropometric values of initially malnourished children in the 1-24-month age group. They concluded that malnutrition on admission in children often remains unrecognized by healthcare workers $^{10}$. As already mentioned, the classical kwashiorkor presentation is rare in children and adolescents with chronic diseases ${ }^{1}$. Our results corroborated these data: in our study groups, we did not find any patients with significant nutritional edema.

Scrimshaw documented the synergistic relationship between malnutrition and infection, representing at the same time the cause and the consequence of an acquired immune deficiency; these phenomena have been amply described since the 1970s. ${ }^{18}$ Many studies have described the prevalence of disease-related malnutrition in hospitalized patients. ${ }^{1,5,11,12}$ Others emphasized the association of malnutrition with discharge, prolonged hospitalization, and the occurrence of pneumonia and weight loss during a hospital stay. ${ }^{11}$ It is possible that doctors and nurses are still unaware of the importance of performing the screening 
and prompt treatment of malnutrition. It is also likely that malnourished patients might present with a variety of atypical symptoms that remain undetected, preventing the diagnosis of malnutrition. ${ }^{10,19}$ Critical illness has a major impact on the nutritional status of both children and adults. ${ }^{2}$ In the present study, the incidence of malnutrition was very high, and moderate or severe malnutrition can provoke a poorer prognosis and a higher mortality odds ratio. ${ }^{19}$ When we analyzed a group of $\mathrm{WN}$ and $\mathrm{MN}$ patients, we found similar results concerning the severity of disease as demonstrated by TISS and PRISM scores. Nevertheless, it is difficult to establish early indicators of a prolonged intensive care unit stay or the impact of malnutrition on mortality rates. Other factors, such as the severity of disease, early need for - and sustained dependence on - mechanical ventilation, inadequate sedation, coma, and type of infection, might also influence mortality rates and hospital stay. ${ }^{19,20}$

Serum IL-6 levels appear to be an ideal marker for detecting early-onset neonatal infection with a high degree of sensitivity and specificity. ${ }^{3}$ Studies have demonstrated that the acute response in severely malnourished children is achieved either through a decrease in catabolism or a combination of increased synthesis and decreased catabolism. ${ }^{21-23}$ It has been reported that albumin alone can underestimate the nutritional risk, while IL- 6 combined with C-reactive protein has been suggested for identifying infected infants in the postnatal period. IL-8 and calcitonin precursors have been used to diagnose infections in neutropenic children. ${ }^{3,23-25}$ In our study, IL-6 concentrations correlated with the severity of illness determined by PRISM and TISS on the first day of hospitalization.

The chronic inflammatory response in patients with severe malnutrition is a controversial subject. Some studies suggest a decrease in inflammatory markers in malnourished patients, while others suggest similar intensity of inflammation compared with well-nourished children. Other reports suggest deregulated cytokine production, with a complex interplay of elevated pro- and anti-inflammatory mediators. ${ }^{25,26} \mathrm{In}$ the present study, both Wn and Mn groups had similar levels of IL-6 on the first and fifth days after hospitalization.

Sepsis is still a major and frequent cause of morbidity and death in ICUs, where early diagnosis and treatment are critical to improved prognoses. The incidence of sepsis was very high in the present study, and serum concentrations of IL-6 were increased in both groups throughout the study (until the $10^{\text {th }}$ day). MN patients had a preserved capacity to increase CRP synthesis. The main effects of this protein are: opsonizing capacity, promotion of chemotaxis and phagocytosis, and stimulation of lymphocyte proliferation and cytotoxicity. Increased acute-phase proteins are of clinical relevance because they may have roles in combating infections. There was a significant decrease of CRP in both $\mathrm{MN}$ and WN children throughout the study. These CRP results, together with the preserved IL- 6 production, suggest that malnourished patients retain the capacity to mount a positive acute-phase response during infection. ${ }^{1,25,26}$

\section{CONCLUSIONS}

The frequency of malnutrition among pediatric ICU patients is very high. Malnutrition is difficult to recognize in a nonspecific hospital population. To be able to correctly identify all malnourished patients, screening of the nutritional status of all newly admitted patients is imperative. Malnutrition may also have contributed to disease severity. Malnourished patients preserve the capacity to release inflammatory markers such as CRP and IL-6, which can be considered favorable for combating infections. Conversely, this release might also have a significant impact on nutritional status during hospitalization.

\section{REFERENCES}

1. Sauerwein RW, Mulder JA, Mulder L, Lowe B, Peshu N, Demacker PNM, et al. Inflammatory mediators in children with protein-energy malnutrition. Am J Clin Nutr. 1997;65:1534-9.

2. Coss-Bu JA, Klish WJ, Walding D, Stein F, Smith EO, Jefferson LS: Energy metabolism, nitrogen balance, and substrate utilization in critically ill children. Am J Clin Nutr. 2001;74:664-9.

3. Messer J, Eyer D, Donato L, Gallati, Matis J, Simeoni U: Evaluation of interleukin-6 and soluble receptors of tumor necrosis factor for early diagnosis of neonatal infection. J Pediatr. 1996;129:574-80.

4. Lyoumi S, Tamion F, Petit J, Déchelotte P, Dauguet C, Scotté M, et al. Induction and modulation of acute-phase response by protein malnutrition in rats: Comparative effect of systemic and localized inflammation on interleukin-6 and acute-phase protein synthesis. J Nutr. 1998;128:166-74.
5. Delgado AF, Kimura HM, Cardoso AL, Uehara D, Carrazza FR. Nutritional follow-up of critically ill infants receiving short term parenteral nutrition. Rev Hosp Clin Fac Med S Paulo. 2000;55:3-8.

6. Correia MI, Waiztberg DL. The impact of malnutrition on morbidity, mortality, length of hospital stay and costs evaluated through a multivariate model analysis. Clin Nutr. 2003;22:219-20.

7. Reid M, Badaloo A, Forrester T, Morlese JF, Heird WC, Jahoor F. The acute-phase protein response to infection in edematous and nonedematous protein-energy malnutrition. Am J Clin Nutr. 2002;76:1409-15.

8. Deitch EA, MA WJ, Ma L, Berg RD, Specian RD. Protein malnutrition presdisposes to inflammatory induced gut origin septic states. Ann Surg. 1990;211:560-7. 
9. Hulst J, Joosten K, Zimmermann L, Hop W, van Buuren S, Büller H, et al. Malnutrition in critically ill children: from admission to 6 months after discharge. Clin Nutr. 2004;23:223-32.

10. Öztürk Y, Büyükgebiz B, Arslan N, Ellidokuz H. Effects of hospital stay on nutritional anthropemetric data in turkish children. J Trop Pediatr. 49:189-90.

11. Rocha GA, Rocha EJ, Martins CV. The effects of hospitalization on the nutritional status of children. J Pediatr. 2006:82:70-4.

12. Motil KJ. Sensitive measures of nutritional status in children in hospital and in the field. Int J Cancer. 1998;11(Suppl):2-9.

13. Falbo AR, Bezerra Alves JG. Severe malnutrition: epidemiological and clinical characteristics of children hospitalized in the Instituto Materno Infantil de Pernambuco (IMIP), Brazil. Cad Saúde Pública. 2002:28:1473-77.

14. Delgado AF. Desnutrição hospitalar. Pediatria (São Paulo): 27:9-11,2005

15. Goldstein B, Giroir B, Randolph A, and the Members of the International Consensus Conference on Pediatric Sepsis: International pediatric sepsis consensus conference: Definitions for sepsis an organ dysfunction in pediatrics. Pediatr Crit Care Med. 2005;6:2-8

16. Pollack MM, Ruttimann UE, Getson PR. Pediatric risk of mortality (PRISM) score. Crit Care Med. 1988;16:1110-6.

17. Fortis A, Mathas M, Laskou M, Kolias S, Maguina N. Therapeutic Intervention Scoring System-28 as a tool of post ICU outcome prognosis and prevention. Minerva Anestesiol. 2004;70:71-81.

18. Scrimshaw NS. Historical concepts of interactions, synergism and antagonism between nutrition and infection. J Nutr. 2003:133:316S-321S
19. Keusch GT. The history of nutrition: malnutrition, infection and immunity. J Nutr. 2003;133:336S-40S.

20. Higgins TL, McGee WT, Steingrub JS, Rapport J, Lemeshow S, Teres D: Early indicators of prolonged intensive care unit stay: Impact of illness severity, physician staffing, and pre-intensive care unit length of stay. Crit Care Med. 2003:31:41-51.

21. Reid M, Badaloo A, Forrester T, Morlese JF, Heird WC, Jahoor F. The acute-phase protein response to infection in edematous and nonedematous protein-energy malnutrition. Am J Clin Nutr. 2002;76:1409-15.

22. Morlese JF, Forrester T, Jahoor F. Acute-phase protein response to infection in severe malnutrion. Am J Physiol. 1998;275:E112-7.

23. Lacour AG, Gervaix A, Zamora SA, Vadas L, Lombard PR, Dayer JM, et al: Procalcitonin, IL-6, IL-8, IL-1 receptor antagonist and Creactive protein as identificators of serious bacterial infections in children with fever without localizing signs. Eur J Pediatr. 2001;160:95-100.

24. Stryjewsky GR, Nylen ES, Bell MJ, Snider RH, Becker KL, WU A, et al. Interleukin-6, interleukin-8, and a rapid and sensitive assay for calcitonin precursors for the determination of bacterial sepsis in febrile neutropenic children. Pediatr Crit Care Med. 2005;6:129-35.

25. Malavé I, Vethencourt MA, Pirela M, Cordero R: Serum levels of thyroxine-binding prealbumin, $\mathrm{C}$-reactive protein and interleukin- 6 in protein-energy undernourished children and normal controls without or with associated clinical infections. J Trop Pediatr. 1998;44:256-62.

26. Bondestam M, Foucard T, Gebre-Medhin M: Serum albumin, retinolbinding protein, thyroxin-binding prealbumin and acute phase reactants as indicators of undernutrition in children with undue susceptibility to acute infections. Acta Paediatr Scand. 1988;77:94-8. 